\title{
miR-182, of the miR-183 cluster family, is packaged in exosomes and is detected in human exosomes from serum, breast cells and prostate cells
}

\author{
BRITTANY L. MIHELICH ${ }^{1}$, SHWETA DAMBAL ${ }^{1}$, SHAOXIA LIN $^{1}$ and LARISA NONN ${ }^{1,2}$ \\ ${ }^{1}$ Department of Pathology, University of Illinois at Chicago; ${ }^{2}$ University of Illinois Cancer Center, Chicago, IL 60612, USA
}

Received March 10, 2016; Accepted May 25, 2016

DOI: $10.3892 / \mathrm{ol} .2016 .4710$

\begin{abstract}
Members of the microRNA (miR)-183 family are expressed at high levels in the majority of cancer types, including breast and prostate, and are considered 'oncomiRs'. The purpose of the present study was to investigate the role of exosomes in cell-to-cell transfer of the miR-183 family, which includes miRs-96, -182 and -183. Despite highly detectable levels of these three miRs within prostate and breast cells in vitro, only miR-182 was detectable in exosomes isolated from cell culture supernatant. Similar to the in vitro results, miR-182 was the only miR detected in exosomes isolated from fresh human serum. The packaging of miR-182 into exosomes was examined in MDA-MB-231 (MDA-182) breast cancer cells with miR-182 overexpression. Levels of mature miR-182 increased in exosomes in a dose-dependent manner compared to intracellular expression. Furthermore, co-culture of MDA-182 cells with naïve MDA-MB-231 cells resulted in an increase in mature miR-182 in the naïve cells, which was blocked by a chemical inhibitor of microvesicle formation. In summary, the present study demonstrates that of the miR-183 family members, miR-182 is preferentially packaged in exosomes, detectable in exosomes from human sera and may be transferred between cells via a microvesicle-dependent mechanism.
\end{abstract}

\section{Introduction}

microRNAs (miRs) are short, non-coding RNAs that canonically function to repress translation and/or initiate degradation of target messenger RNAs (mRNAs) (1). The members of the miR-183 family, which are transcribed as the polycistronic miR-183-96-182 cluster (1), are consistently expressed at high levels in a number of human cancer types, including hormone-dependent breast and prostate cancer (1-8). When these miRs are overexpressed in cell cultures they behave

Correspondence to: Professor Larisa Nonn, Department of Pathology, University of Illinois at Chicago, 840 South Wood Street, Room 130 CSN, MC 847, Chicago, IL 60612, USA

E-mail:1nonn@uic.edu

Key words: microRNA-182, exosomes, breast, prostate primarily as oncogenes or 'oncomiRs', and alter phenotypes consistent with transformation and oncogenesis, including cell proliferation, migration, invasion and xenograft growth (2-8).

In addition to their intracellular role, mature miRs are present in secretory vesicles, which may facilitate cell-to-cell transfer of miRs (9-12). Exosomes are a subclass of such vesicles, which are 50-150 $\mathrm{nm}$ in size, and are released from the majority of cell types $(12,13)$. Exosomes were discovered in the 1980s in mammalian reticulocytes and were originally thought to be a mechanism for the cell to rid itself of waste (14). However, exosomes are now known to contain valuable cellular material including RNA, DNA and proteins $(10,15,16)$. Cells may take up exosomes by fusion (17) or by internalization, and thus exosomes are mediators of cell-to-cell communication (18). miRs within exosomes are functional in the receiving cells $(9,10,16)$ and, in the context of cancer, may act on nearby cells to modify the local microenvironment during carcinogenesis $(16,19,20)$.

The majority of circulating miRs are within exosomes (21); thus, exosomes are potentially a cancer-specific source of miR biomarkers (21-23). Circulating miRs have been isolated and examined as biomarkers for breast and prostate cancer $(24,25)$, but, to the best of our knowledge, few studies have focused specifically on miRs within exosomes.

Given the well-documented oncogenic role of the miR-183 family in breast and prostate cancer and the emerging role of exosomes in miR trafficking, the present study examined the levels of these miRs in exosomes isolated from cultured breast and prostate cancer cells. In addition, the present study examined miR-182 levels in exosomes from cells with stable miR-182 overexpression, and investigated cell-to-cell transfer of miR-182 via exosomes. The expression of the miR-183 family was also determined in exosomes isolated from fresh serum.

\section{Materials and methods}

Cell culture and patient samples. Prostate and breast cell lines were maintained as recommended by the supplier [American Type Culture Collection (ATCC), Manassas, Virginia, USA]. Prostate cell lines, RWPE-1 and RWPE-2, were cultured in keratinocyte serum-free media (Thermo Fisher Scientific, Inc., Waltham, MA, USA) supplemented with bovine pituitary extract (BPE) (Thermo Fisher Scientific, Inc.) and epidermal growth factor (EGF) (Thermo Fisher Scientific, Inc.), as 
recommended by the ATCC. The DU145 prostate cell line was cultured in Dulbecco's modified Eagle's medium (Thermo Fisher Scientific, Inc.) supplemented with $10 \%$ fetal bovine serum (FBS) (Sigma-Aldrich, St. Louis, MO, USA). The PC3 prostate cell line was cultured in RPMI-1640 media (Thermo Fisher Scientific, Inc.) supplemented with $10 \%$ FBS. Primary prostate epithelial cells (PrE) were derived at University of Illinois at Chicago (Chicago, IL, USA; University of Illinois at Chicago Cancer Center IRB-approved protocol) as previously described $(6,26,27)$ and cultured in prostate epithelial cell growth medium (PrEGM; Lonza Group, Basel, Switzerland) supplemented with BPE, cholera toxin (Sigma-Aldrich) and EGF. For $48 \mathrm{~h}$ prior to exosome collection, the PrEGM was not supplemented with BPE, and all cell lines that require FBS were supplemented with exosome-free FBS. All cells were harvested or used for exosome isolation at $70 \%$ cell density.

A total of three sets of pooled de-identified serum were collected under an IRB-approved protocol from male and female patients at University of Illinois at Chicago Hospital (Chicago, IL, USA). A total of $10 \mathrm{ml}$ each from five patients of fresh, never frozen sera was combined to provide $50 \mathrm{ml}$ total for exosome isolation.

Overexpression of miR-182 in MDA-MB-231 cells. MDA-MB-231 cells were transfected with pCMV-MIR (scrambled or miR-182; OriGene Technologies, Inc., Rockville, MD, USA) using Lipofectamine (Thermo Fisher Scientific, Inc.) and selected with Geneticin (G418; Sigma-Aldrich) according to the manufacturer's protocol. Following transfection, subpopulations were clonally selected with G418 and measured for miR expression by reverse transcription-quantitative polymerase chain reaction (RT-qPCR). One negative scramble miR control (miR-NEG) and two miR-182 overexpressing clones (182-1 and 182-7) were used in the experiments.

Exosome isolation. Prior to isolation, exosome-free FBS was prepared by two sequential $100,000 \times \mathrm{g}$ centrifugations at $4^{\circ} \mathrm{C}$ of 70 min each. For PrE and RWPE cells, BPE was omitted from culture medium $48 \mathrm{~h}$ prior to collection for exosome isolation. To collect cell-derived exosomes, cells were plated on five $100 \mathrm{~mm}$ dishes. When cells reached $70 \%$ density, they were washed twice with 1X HEPES-buffered saline and the media was replaced with exosome-depleted media. Following $48 \mathrm{~h}$ of incubation, the media was harvested and exosomes isolated by differential centrifugation as previously described (28). Briefly, cells were removed by a spin at $300 \mathrm{x} \mathrm{g}$ at $4^{\circ} \mathrm{C}$ for $10 \mathrm{~min}$. The supernatant containing the exosomes was removed and centrifuged at $2,000 \mathrm{x} \mathrm{g}$ at $4^{\circ} \mathrm{C}$ for $20 \mathrm{~min}$. Supernatant was subsequently placed in polycarbonate bottles and ultracentrifuged at $10,000 \mathrm{x} \mathrm{g}$ at $4^{\circ} \mathrm{C}$ for $30 \mathrm{~min}$, and the resulting supernatant was put into a clean polycarbonate bottle and centrifuged at $100,000 \mathrm{x} \mathrm{g}$ at $4^{\circ} \mathrm{C}$ for $70 \mathrm{~min}$. The supernatant was discarded and exosomes were washed in $1 \mathrm{X}$ phosphate-buffered saline (PBS), and subsequently repelleted at $100,000 \mathrm{x} \mathrm{g}$ at $4^{\circ} \mathrm{C}$ for $70 \mathrm{~min}$. The supernatant was discarded and exosomes were harvested in $100 \mu \mathrm{l} 1 \mathrm{X}$ PBS. Collected exosomes were subjected to RNase A treatment for $1 \mathrm{~h}$ at $37^{\circ} \mathrm{C}$ prior to RNA analysis.

Human serum exosomes were isolated by an identical procedure starting with $50 \mathrm{ml}$ of serum diluted with $1 \mathrm{X}$ PBS to completely fill the polycarbonate ultracentrifuge bottles.
Transmission electron microscopy. A total of $20 \mu \mathrm{l}$ of isolated exosomes were placed on copper coated grids and allowed to settle for $5 \mathrm{~min}$. Grids were subsequently stained with $20 \mu \mathrm{l}$ of uranyl acetate (Sigma-Aldrich) for $1 \mathrm{~min}$. Grids were allowed to dry overnight prior to viewing and were analyzed on a JEM-1220 transmission electron microscope (JEOL, Ltd., Tokyo, Japan).

Exosome quantification. Exosome number was quantified using enzyme-linked immunosorbent assay (ELISA) for cluster of differentiation (CD)81 [breast cells (29)] and CD9 [prostate cells (30)]. ELISAs were performed according to the manufacturer's protocol (System Biosciences, Palo Alto, CA, USA) on freshly harvested exosomes. Prior to cell treatment with isolated exosomes, the cell number was determined for the exosome-donating cells, and the exosome number was normalized to the cell number between treatment and controls for each cell line.

$R T$ - $q P C R$. RNA was extracted using the TRIzol reagent (Thermo Fisher Scientific, Inc.) according to manufacturer's protocol for preservation of small RNAs. RNA for miR detection was reverse transcribed using the Universal cDNA Synthesis kit (Exiqon, Inc., Woburn, MA, USA) with $100 \mathrm{ng}$ RNA, under the following conditions: $60 \mathrm{~min}$ at $42^{\circ} \mathrm{C}$, followed by $5 \mathrm{~min}$ at $95^{\circ} \mathrm{C}$ and hold at $4^{\circ} \mathrm{C}$. qPCR was performed on the cDNA using the ExiLENT SYBR Green Master mix (Exiqon, Inc.) according to the manufacturer's protocol. The StepOne Plus Real-Time PCR System (Thermo Fisher Scientific, Inc.) was used for detection and quantitation. The following cycling conditions were employed for $\mathrm{qPCR}: 95^{\circ} \mathrm{C}$ for $10 \mathrm{~min}$, followed by 40 cycles of $95^{\circ} \mathrm{C}$ for $10 \mathrm{sec}$ and $60^{\circ} \mathrm{C}$ for $1 \mathrm{~min}$. Primers for the following were used: small nucleolar RNA U66 (snoR-U66) (product no. 203905), miR-96 (product no. 204417), miR-182 (product no. 206070) and miR-183 (product no. 206030; Exiqon, Inc.). Relative quantity was calculated by the $\Delta \Delta \mathrm{Cq}$ method (31) and normalized to snoR-U66.

Luciferase reporter for miR-182 activity. LightSwitch Synthetic miR Target GoClone Reporter for miR-182 and the empty vector were purchased from SwitchGear Genomics (Menlo Park, CA, USA). The LightSwitch vector contains a Renilla luciferase gene with a synthetic 3' untranslated region (UTR) with repeats of the miR-182 binding site. A total of $50 \mathrm{ng}$ of LightSwitch and 50 ng of pGL4-empty vector (Promega Corporation, Madison, WI, USA) were co-transfected into MDA-231-MB cells with Dharmafect (Dharmacon; GE Healthcare Life Sciences, Chalfont, UK). Luciferase activity was measured $24 \mathrm{~h}$ later with the Dual-Luciferase ${ }^{\circledR}$ Assay (Promega Corporation). Lightswitch Renilla activity was normalized to pGL4 to assess transfection efficiency.

Co-culture. Naïve MDA-MB-231 cells were seeded into a 12-well plate and 182-1, 182-7 or NEG control cells were seeded in inserts. After $24 \mathrm{~h}$ of incubation at $37^{\circ} \mathrm{C}$ in $5 \% \mathrm{CO}_{2}$, the inserts were placed into the wells containing the naïve cells with and without $10 \mu \mathrm{M}$ of microvesicle release inhibitor hydrochloride hydrate (GW4869; Sigma-Aldrich; dimethyl sulfoxide as a control) and were co-cultured for 5 days at $37^{\circ} \mathrm{C}$ in $5 \% \mathrm{CO}_{2}$. The medium and GW4869 were replaced after 
A

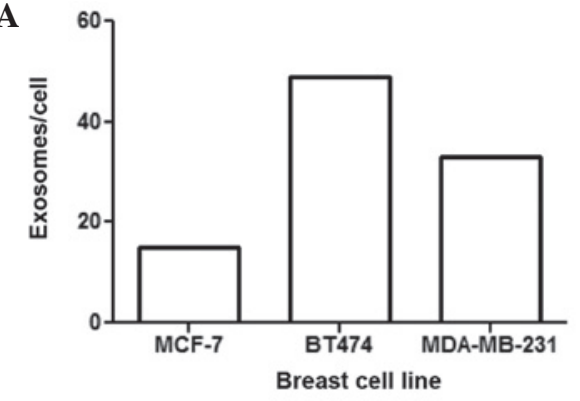

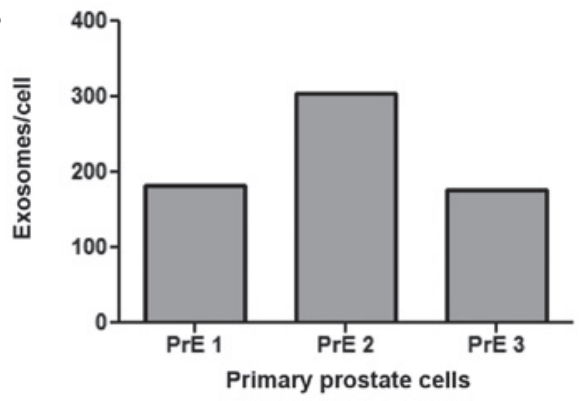

C

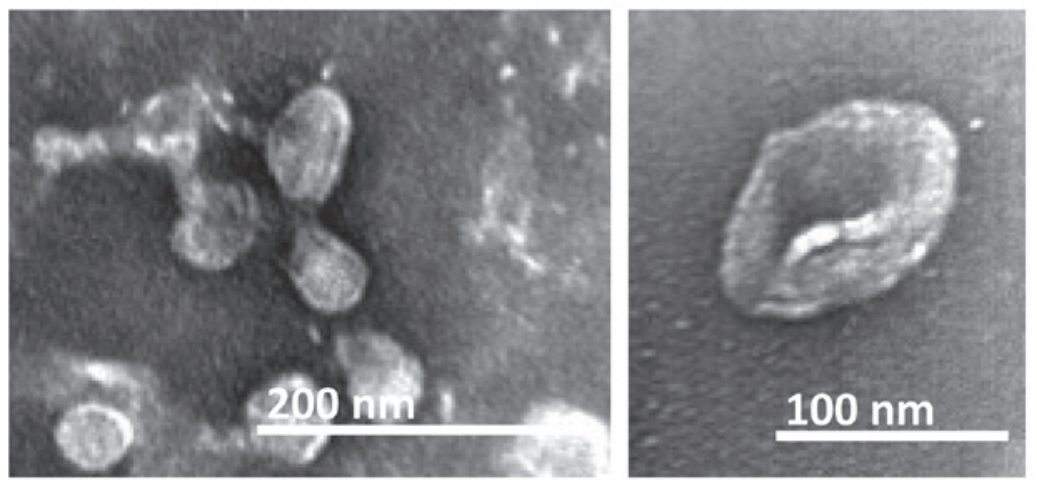

Figure 1. Exosomes are produced by breast and prostate cells. ELISA quantification of exosomes isolated from (A) breast and (B) prostate cells (one exosome isolation for each cell line). ELISA for CD81 exosome surface antigen was used to quantify the number of exosomes produced per cell in the MCF-7, BT474, and MDA-MB-231 (MB-231) breast cancer cell lines. ELISA for CD9 exosome surface antigen was used to quantify the number of exosomes produced per cell in benign primary prostate epithelial cells derived from three distinct prostate cancer patients (PrE 1, PrE 2 and PrE 3). (C) Representative transmission electron micrograph of isolated exosomes (exosomes from MDA-MB-231 cells shown). ELISA, enzyme-linked immunosorbent assay; CD, cluster of differentiation.

$72 \mathrm{~h}$. Cells were collected following five days of co-culture and miR-182 levels were measured by RT-qPCR in the naïve cells.

Statistical analysis. Statistical analysis was performed by Student's t-test in GraphPad Prism 5 software (GraphPad Software, Inc., La Jolla, CA, USA). It was noted that when the repeat experiments had values of zero, the t-test was not valid. $\mathrm{P}<0.05$ was considered to indicate a statistically significant difference.

\section{Results}

Exosomes are produced by breast and prostate cells. The present study examined exosome production from several prostate and breast cell lines. Exosomes were isolated by ultracentrifugation and quantified by ELISA. CD81 was used for breast cancer cells (29) and CD9 was used for prostate cells (30) based on previous reports. All of the breast cancer cell lines examined (MCF-7, BT474, and MDA-MB-231) released exosomes (Fig. 1A). A total of three distinct patient-derived primary prostate cell (PrE) populations also secreted exosomes (Fig. 1B).

Transmission electron micrographs (TEM) confirmed that the isolated vesicles were exosomes and were the correct shape and size in the range of 50-150 nM. Representative TEM images of exosomes from MDA-MB-231 cells are presented in Fig. 1C.

miR-182 is present in exosomes from breast and prostate cell lines and human serum. Intracellular and exosomal levels of the miR-183 family members were compared in five prostate and three breast cell lines (Fig. 2A-D). Although miRs-183,
-96 and -182 were all present intracellularly, only miR-182 was robustly detected in the exosomes (Fig. 2C and D). Notably, RWPE-1 benign immortalized prostate epithelial cell line and DU145 prostate cancer cell line cells expressed miR-182 at high levels, but did not have detectable miR-182 in their exosomes. In the breast cancer cell lines, MDA-MB-231 cells had the lowest amount of miR-182 in the exosomes compared with MCF-7 and BT474 cells.

Exosomes were isolated from fresh human serum to determine the presence of miR-183 family members. A total of three independent sets of pooled male and female serum were used for exosome isolation. miR-182 (Fig. 2E), but not miRs-183 and 96, was detected in exosomes from males and females. These data indicate that miR-182 is preferentially packaged into exosomes in all the cell lines examined, as well as present in human patient sera.

Overexpression of miR-182 in MDA-MB-231 breast cancer cells dose-dependently increases exosome levels of miR-182. To determine if an increase in intracellular miR-182 would alter miR-182 levels in exosomes, miR-182 was stably overexpressed in the MDA-MB-231 breast cancer cell line. MDA-MB-231 cells were used for these experiments as they had the lowest level of miR-182 in the exosome experiments. miR-182 was overexpressed using a hairpin premiR expression plasmid, resulting in a 10 - to 50-fold increase in miR-182, as compared with the miR-NEG scrambled hairpin control (Fig. 3A). Exosomes isolated from the media of the MDA-182 cells dose-dependently increased miR-182 10- to 50-fold compared with the miR-NEG control (Fig. 3B). To adjust for potential differences in cell density during exosome 
A

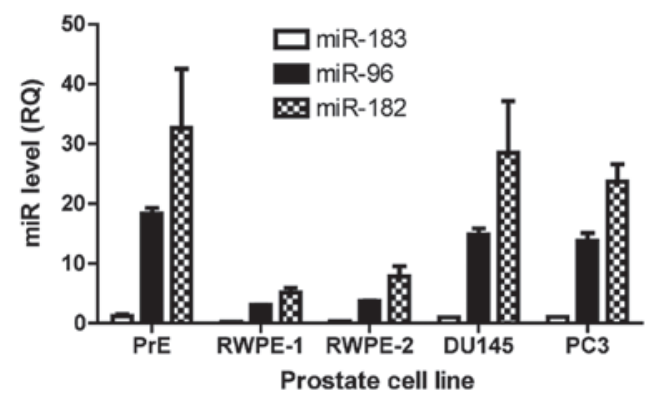

C

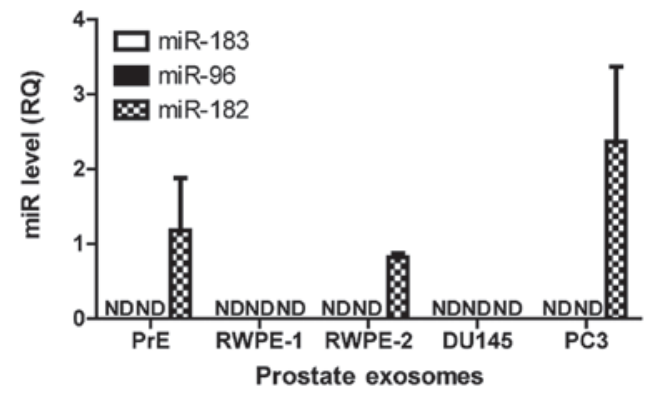

$\mathbf{E}$

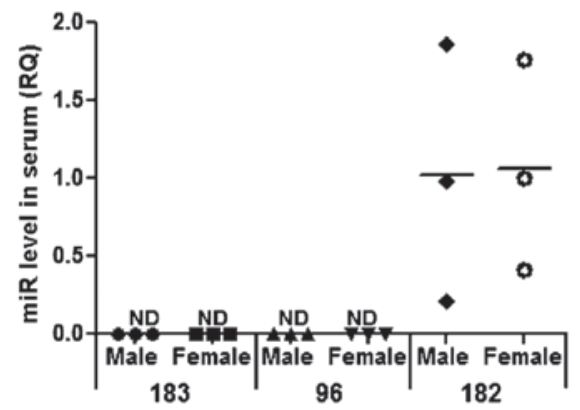

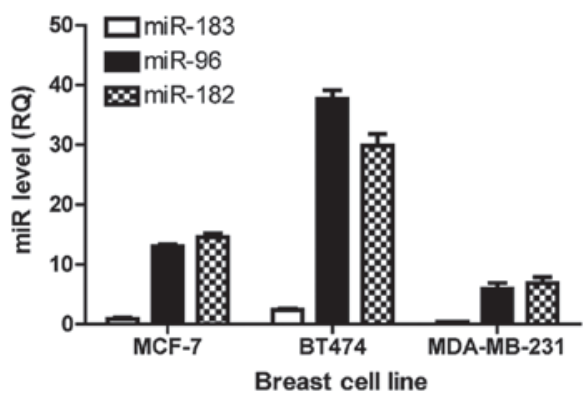

D

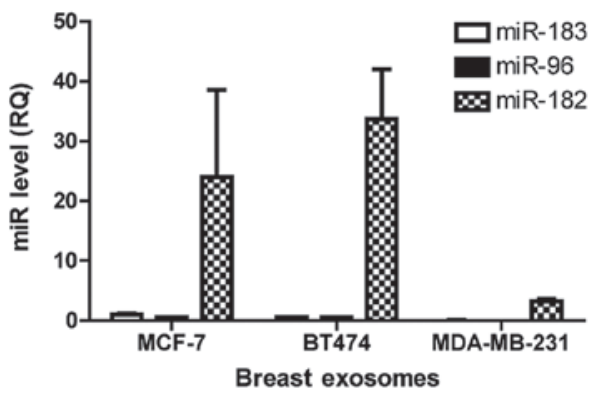

Figure 2. miR-182 is present in exosomes from breast cells, prostate cells and human serum. RT-qPCR analyses of the miR-183 family members (miR-183, miR-96 and miR-182) in (A) prostate cells (PrE, RWPE-1. RWPE-2, DU145 and PC3), (B) breast cells (MCF7, BT474 and MDA-MB-231), (C) exosomes secreted by prostate cells and (D) exosomes secreted by breast cells. Bar graphs are representative of at least 3 experiments. Data are presented as the mean \pm standard deviation. (E) RT-qPCR analyses of miR-183, -96 and -182 in pooled serum from men and women. The graph shows three independent pooled serum samples from male and female donors. RQ is shown normalized to small nucleolar RNA U66. miR, microRNA; RT-qPCR, reverse transcription-polymerase chain reaction; $\mathrm{RQ}$, relative quantity; $\mathrm{ND}$, not detected.

collection, RNA input was normalized to the cell number. Activity of the overexpressed miR-182 was confirmed via the reduction in luciferase activity of a synthetic $3^{\prime}$ UTR reporter (Fig. 3C).

It has been reported that miR-182 is only present in its mature form in exosomes (16) in contrast to other miRs that are present as premiRs and mature miRs in exosomes (16). In the MDA-182 cells the premiR-182 was only detectable intracellularly and not in the exosomes (Fig. 3D). Furthermore, levels of premiR-182 were not significantly different in the MDA-182 clones compared with MDA-NEG, suggesting a short half-life for premiR-182 RNA. These data show that in these cells increased miR-182 expression resulted in increased levels of the mature miR in the exosomes.

Cell-to-cell transfer of miR-182 in MDA-MB-231 cells by exosomes. Experiments were designed to determine if miR-182 can be transferred between cells via exosome-mediated mechanisms. This was achieved by two methods: Co-culture of cells and direct transfer of isolated exosomes. MDA-182-1 cells were selected for the following experiments as this clone had an elevated expression of miR-182 without alterations in cell proliferation. MDA-182-1 cells were co-cultured with naïve MDA-MB-231 cells (Fig. 4A), resulting in an increase in miR-182 in the naïve cells (Fig. 4A). Addition of GW4869, an inhibitor of microvesicle release (32), blocked this increase, demonstrating that the transfer of miR-182 between cells was dependent on microvesicle transfer (Fig. 4A). Furthermore, direct transfer of isolated exosomes from MDA-182-1 cells to the naïve MDA-MB-231 cells significantly increased levels of miR-182 in the naïve cells (Fig. 4B).

\section{Discussion}

The miR content of cancer cell-derived exosomes varies based on aggressiveness of phenotype $(33,34)$, and cancer cells secrete increased exosomal miR compared with normal cells (16). Consistent with these previous findings, the present study demonstrated that prostate and breast cancer cells, as well as noncancerous prostate cells, secrete exosomes. Furthermore, the present study demonstrated that miR-182 expression and secretion changes with breast cancer cell line aggressiveness. 

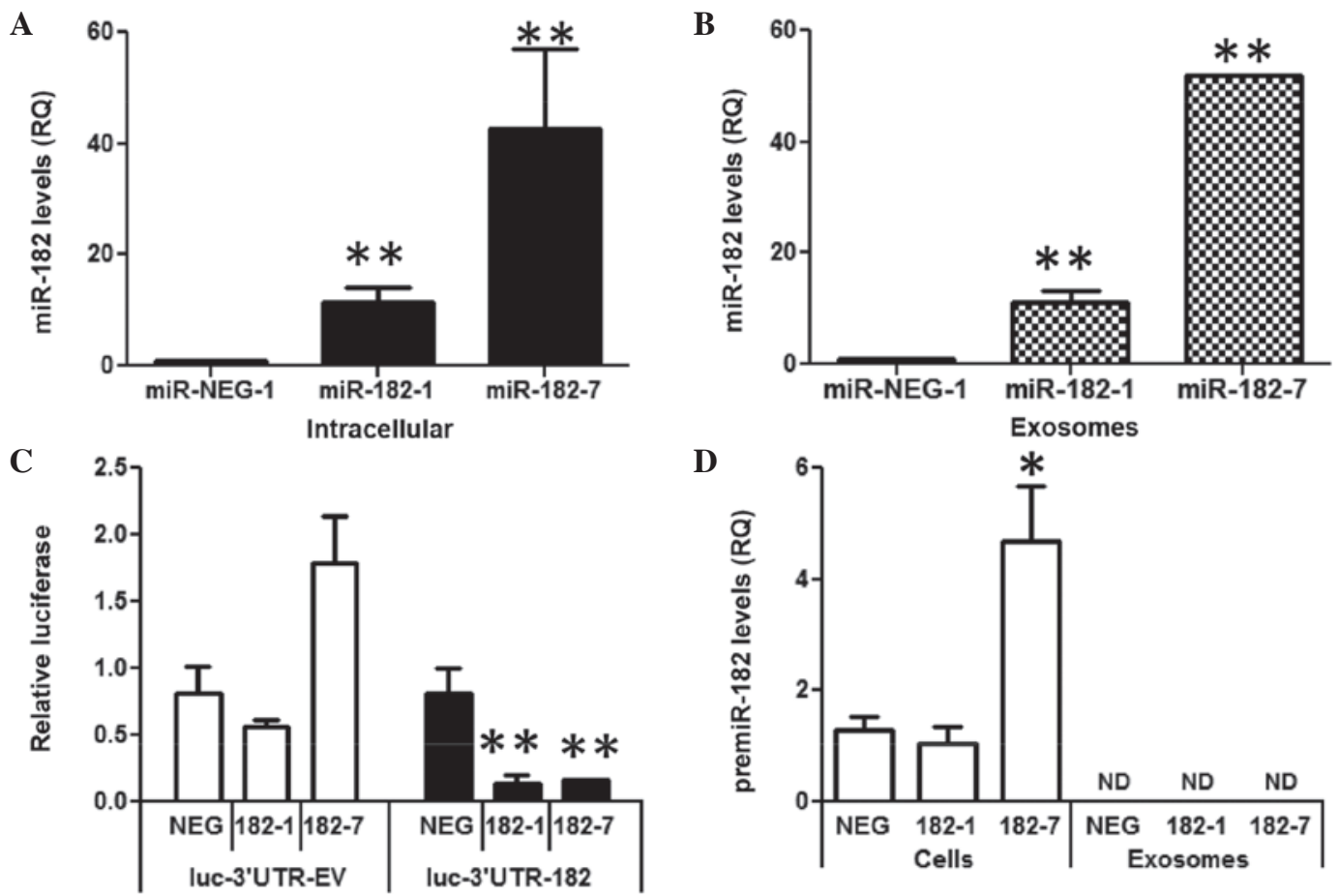

Figure 3. Overexpression of miR-182 in MDA-231-MB cells increases intracellular and exosomal mature miR-182. (A) Intracellular miR-182 levels in 2 clones of MDA-MB-231 cells stably overexpressed miR-182, as compared to an miR-NEG-1 clone, assessed by RT-qPCR. (B) Levels of miR-182 in exosomes isolated from two clones of MDA-MB-231 cells stably overexpressing miR-182, as compared to an miR-NEG-1 clone, assessed by RT-qPCR. (C) Luciferase activity of a reporter with a 3' untranslated region containing miR-182 binding sites or EV. (D) premiR-182 expression in MDA-NEG, MDA-182-1 and MDA-182-7 cells and exosomes, assessed by RT-qPCR. Data are presented as the mean \pm standard error of three replicate experiments. ${ }^{* *} \mathrm{P} \leq 0.01$ and ${ }^{*} \mathrm{P} \leq 0.05$ compared with the negative control, assessed by Student's t-test. miR, microRNA; RT-qPCR, reverse transcription-polymerase chain reaction; EV, empty vector; NEG, negative control; RQ, relative quantity; ND, not detected.

A

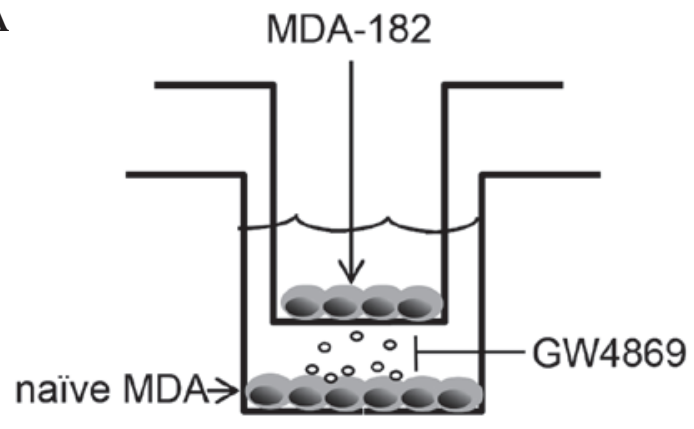

B

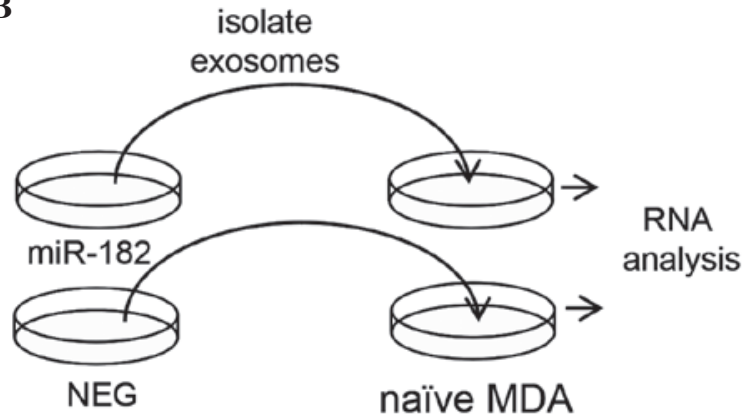

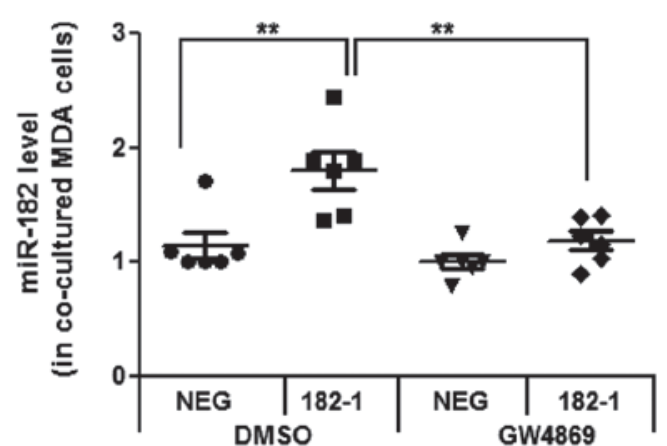

Cells on co-culture insert

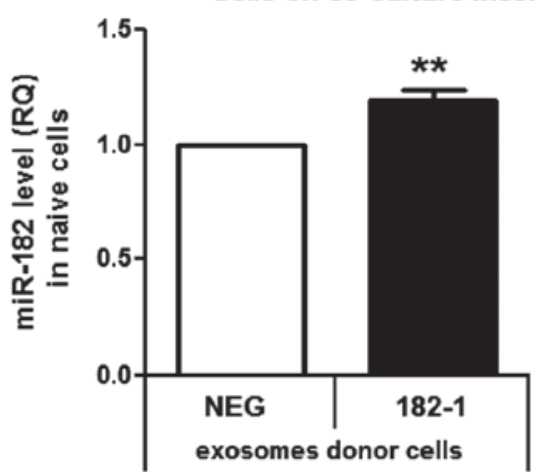

Figure 4. Cell-to-cell transfer of miR-182 in exosomes to naïve MDA-MB-231 cells. (A) Naïve MDA-MB-231 cells were co-cultured with MDA-182-1 or NEG cells in the insert. miR-182 levels were measured by reverse transcription-quantitative polymerase chain reaction in the naïve cells following 5 days of co-culture with DMSO (vehicle) or $2 \mu \mathrm{M} \mathrm{GW} 4869$. Data points from three experiments are presented, and error bars represent the standard error. (B) miR-182 levels in naïve MDA-MB-231 cells following incubation with isolated exosomes from miR-182-1 or NEG-1 cells. Data are presented as the mean \pm standard error of three replicate experiments. ${ }^{* * *} \mathrm{P} \leq 0.01$ compared with the negative control. miR, microRNA; NEG, negative control; GW4869, dihydrochloride hydrate; DMSO, dimethyl sulfoxide; RQ, relative quantity. 
The present study has two significant findings that have not been previously shown to the best of our knowledge: i) miR-182 is the only member of the miR-183 family detected in exosomes from human serum and multiple breast/prostate cell types, and ii) overexpression of miR-182 dose-dependently increased miR-182 in exosomes. miR-183, miR-96 and miR-182 have all been identified to be overexpressed in prostate and breast cancer tissues (35); however, the present study observed miR-182 to be present at significantly increased levels in exosomes compared to miR-96 and miR-183. miR-182 may be selectively packaged into exosomes. Alternatively, as miR-182 is expressed at the highest level of the three miRs in the cluster, it may be passively taken up into the vesicles. Regardless of the mechanism for preferential miR-182 packaging, the results of the present study suggest that miR-182, more than the other miR-183 family members, may have significance in cell-cell communication via microvesicle transfer.

The present study complements a previous study by Melo et al (16), who demonstrated that miR-182 could be transferred between cells and that miR-182 is secreted exclusively as a mature miR, unlike other exosomal miRs that are secreted as premiRs and processed to the mature form within exosomes (16). The present study additionally did not detect premiR-182 in any of the exosomes, which was consistent with the data from Melo et al (16). The present study also observed that exosomes facilitated transfer of miR-182 in breast cancer cells, as exosomes derived from miR-182 overexpressing breast cancer cells were able to increase the cellular concentration of miR-182 in receiving cells. Melo et al (16) additionally demonstrated that miR-182 from MDA-231-MB exosomes was functional and led to decreased mRNA target levels and altered the phenotype of receiving cells. Therefore, miR-182, not miRs-96 or -183 , is likely to contribute to the cancer microenvironment.

In addition to their known functions within cells, miRs have been reported to be present at varying levels in the circulation of cancer patients, suggesting that they may have utility as biomarkers for diagnosis or prognosis (36-38). miRs are stable in the serum (36) and thus are attractive candidates for biomarkers. The miR-183 cluster members are consistently overexpressed in breast cancer tissues (39). miR-182 specifically has been observed to be present at higher levels in the serum of breast cancer patients and may be used to distinguish between estrogen receptor and progesterone receptor positive breast cancers $(35,39)$. However, it remains to be elucidated whether the serum miR-182 is within exosomes and, if it is, where these exosomes originate. The present study observed that miR-182, and not the remaining miR-183 family members, was detected within exosomes from human male and female serum. However, the present study did not examine differential levels of miR-182 in cancer patients. The results of the present study suggest that utility of serum miR-182 as a biomarker may be improved if exosomes are examined.

The results of the present study support and complement existing findings to demonstrate that the miR content of cancer cell-derived exosomes varies based on the aggressiveness of the cell $(33,34)$. Furthermore, it was demonstrated that miR-182 is the miR-183 family member that is trafficked by exosomes in the investigated cell types and in human serum. Given the oncogenic role of miR-182, increased exosomal levels of miR-182 in breast cancer may not only contribute to disease aggressiveness, but may additionally be exploited as a biomarker. Future studies are required to elucidate whether miR-182 in exosomes is functionally relevant to carcinogenesis and/or a biomarker of disease prognosis.

\section{Acknowledgements}

The authors would like to thank Dr. Linda Juarez (University of Illinois at Chicago) for assistance with transmission electron microscopy experiments. The present research was supported by the National Institutes of Health (grant no. R01-CA166588) and University of Illinois in Chicago Center for Clinical and Translational Sciences Pre-doctoral Education for Clinical and Translational Scientists Fellowship.

\section{References}

1. Dambal S, Shah M, Mihelich B and Nonn L: The microRNA-183 cluster: The family that plays together stays together. Nucleic Acids Res 43: 7173-7188, 2015.

2. Hannafon BN, Sebastiani P, de las Morenas A, Lu J and Rosenberg CL: Expression of microRNA and their gene targets are dysregulated in preinvasive breast cancer. Breast Cancer Res 13: R24, 2011.

3. Hirata H, Ueno K, Shahryari V, Deng G, Tanaka Y, Tabatabai ZL, Hinoda Y and Dahiya R: MicroRNA-182-5p promotes cell invasion and proliferation by down regulating FOXF2, RECK and MTSS1 genes in human prostate cancer. PLoS One 8: e55502, 2013.

4. Lin H, Dai T, Xiong H, Zhao X, Chen X, Yu C, Li J, Wang X and Song L: Unregulated miR-96 induces cell proliferation in human breast cancer by downregulating transcriptional factor FOXO3a. PLoS One 5: e15797, 2010.

5. Lowery AJ, Miller N, Dwyer RM and Kerin MJ: Dysregulated miR-183 inhibits migration in breast cancer cells. BMC Cancer 10: 502, 2010.

6. Mihelich BL, Khramtsova EA, Arva N, Vaishnav A, Johnson DN, Giangreco AA, Martens-Uzunova E, Bagasra O, Kajdacsy-Balla A and Nonn L: miR-183-96-182 cluster is overexpressed in prostate tissue and regulates zinc homeostasis in prostate cells. J Biol Chem 286: 44503-44511, 2011.

7. Schaefer A, Jung M, Mollenkopf HJ, Wagner I, Stephan C, Jentzmik F, Miller K, Lein M, Kristiansen G and Jung K: Diagnostic and prognostic implications of microRNA profiling in prostate carcinoma. Int J Cancer 126: 1166-1176, 2010.

8. Ueno K, Hirata H, Shahryari V, Deng G, Tanaka Y, Tabatabai ZL, Hinoda Y and Dahiya R: microRNA-183 is an oncogene targeting Dkk-3 and SMAD4 in prostate cancer. Br J Cancer 108: 1659-1667, 2013.

9. Montecalvo A,Larregina AT, Shufesky WJ, Stolz DB, Sullivan ML, Karlsson JM, Baty CJ, Gibson GA, Erdos G, Wang Z, et al: Mechanism of transfer of functional microRNAs between mouse dendritic cells via exosomes. Blood 119: 756-766, 2012.

10. Valadi H, Ekström K, Bossios A, Sjöstrand M, Lee JJ and Lötvall JO: Exosome-mediated transfer of mRNAs and microRNAs is a novel mechanism of genetic exchange between cells. Nat Cell Biol 9: 654-659, 2007.

11. Chevillet JR, Kang Q, Ruf IK, Briggs HA, Vojtech LN, Hughes SM, Cheng HH, Arroyo JD, Meredith EK, Gallichotte EN, et al: Quantitative and stoichiometric analysis of the microRNA content of exosomes. Proc Natl Acad Sci USA 111: 14888-14893, 2014.

12. Koga K, Matsumoto K, Akiyoshi T, Kubo M, Yamanaka N, Tasaki A, Nakashima H, Nakamura M, Kuroki S, Tanaka M and Katano M: Purification, characterization and biological significance of tumor-derived exosomes. Anticancer Res 25: 3703-3707, 2005 .

13. Dragovic RA, Gardiner C, Brooks AS, Tannetta DS, Ferguson DJ, Hole P, Carr B, Redman CW, Harris AL, Dobson PJ, et al: Sizing and phenotyping of cellular vesicles using nanoparticle tracking analysis. Nanomedicine 7: 780-788, 2011.

14. Trams EG, Lauter CJ, Salem N Jr and Heine U: Exfoliation of membrane ecto-enzymes in the form of micro-vesicles. Biochim Biophys Acta 645: 63-70, 1981. 
15. Johnstone RM, Adam M, Hammond JR, Orr L and Turbide C: Vesicle formation during reticulocyte maturation. Association of plasma membrane activities with released vesicles (exosomes). J Biol Chem 262: 9412-9420, 1987.

16. Melo SA, Sugimoto H, O'Connell JT, Kato N, Villanueva A, Vidal A, Qiu L, Vitkin E, Perelman LT, Melo CA, et al: Cancer exosomes perform cell-independent microRNA biogenesis and promote tumorigenesis. Cancer Cell 26: 707-721, 2014.

17. Parolini I, Federici C, Raggi C, Lugini L, Palleschi S, De Milito A, Coscia C, Iessi E, Logozzi M, Molinari A, et al: Microenvironmental $\mathrm{pH}$ is a key factor for exosome traffic in tumor cells. J Biol Chem 284: 34211-34222, 2009.

18. Keller S, König AK, Marmé F, Runz S, Wolterink S, Koensgen D, Mustea A, Sehouli J and Altevogt P: Systemic presence and tumor-growth promoting effect of ovarian carcinoma released exosomes. Cancer Lett 278: 73-81, 2009.

19. Jang JY, Lee JK, Jeon YK and Kim CW: Exosome derived from epigallocatechin gallate treated breast cancer cells suppresses tumor growth by inhibiting tumor-associated macrophage infiltration and M2 polarization. BMC Cancer 13: 421, 2013.

20. Umezu T, Ohyashiki K, Kuroda M and Ohyashiki JH: Leukemia cell to endothelial cell communication via exosomal miRNAs. Oncogene 32: 2747-2755, 2013.

21. Gallo A, Tandon M, Alevizos I and Illei GG: The majority of microRNAs detectable in serum and saliva is concentrated in exosomes. PLoS One 7: e30679, 2012.

22. Cheng L, Sharples RA, Scicluna BJ and Hill AF: Exosomes provide a protective and enriched source of miRNA for biomarker profiling compared to intracellular and cell-free blood. J Extracell Vesicles 3: 2014.

23. Taylor DD and Gercel-Taylor C: MicroRNA signatures of tumor-derived exosomes as diagnostic biomarkers of ovarian cancer. Gynecol Oncol 110: 13-21, 2008.

24. Mihelich BL, Maranville JC, Nolley R, Peehl DM and Nonn L: Elevated serum microRNA levels associate with absence of high-grade prostate cancer in a retrospective cohort. PLoS One 10: e0124245, 2015.

25. Wang F, Zheng Z, Guo J and Ding X: Correlation and quantitation of microRNA aberrant expression in tissues and sera from patients with breast tumor. Gynecol Oncol 119: 586-693, 2010

26. Peehl DM: Are primary cultures realistic models of prostate cancer? J Cell Biochem 91: 185-195, 2004.

27. Peehl DM: Primary cell cultures as models of prostate cancer development. Endocr Relat Cancer 12: 19-47, 2005.

28. Théry C, Amigorena S, Raposo G and Clayton A: Isolation and characterization of exosomes from cell culture supernatants and biological fluids. Curr Protoc Cell Biol Chapter 3: Unit 3.22, 2006.
29. Luga V, Zhang L, Viloria-Petit AM, Ogunjimi AA, Inanlou MR, Chiu E, Buchanan M, Hosein AN, Basik M and Wrana JL: Exosomes mediate stromal mobilization of autocrine Wnt-PCP signaling in breast cancer cell migration. Cell 151: 1542-1556, 2012.

30. Jansen FH, Krijgsveld J, van Rijswijk A, van den Bemd GJ, van den Berg MS, van Weerden WM, Willemsen R, Dekker LJ, Luider TM and Jenster G: Exosomal secretion of cytoplasmic prostate cancer xenograft-derived proteins. Mol Cell Proteomics 8: 1192-1205, 2009.

31. Livak and Schmittgen: Analysis of relative gene expression data using real-time quantitative PCR and the $2-\Delta \Delta \mathrm{Ct}$ method. Methods 25: 402-408, 2001.

32. Trajkovic K, Hsu C, Chiantia S, Rajendran L, Wenzel D, Wieland F, Schwille P, Brügger B and Simons M: Ceramide triggers budding of exosome vesicles into multivesicular endosomes. Science 319: 1244-1247, 2008.

33. Llorente A, Skotland T, Sylvänne T, Kauhanen D, Róg T, Orłowski A, Vattulainen I, Ekroos K and Sandvig K: Molecular lipidomics of exosomes released by PC-3 prostate cancer cells. Biochim Biophys Acta 1831: 1302-1309, 2013.

34. Ohshima K, Inoue K, Fujiwara A, Hatakeyama K, Kanto K, Watanabe Y, Muramatsu K, Fukuda Y, Ogura S, Yamaguchi K and Mochizuki T: Let-7 microRNA family is selectively secreted into the extracellular environment via exosomes in a metastatic gastric cancer cell line. PLoS One 5: e13247, 2010.

35. Zhang QH, Sun HM, Zheng RZ, Li YC, Zhang Q, Cheng P, Tang ZH and Huang F: Meta-analysis of microRNA-183 family expression in human cancer studies comparing cancer tissues with noncancerous tissues. Gene 527: 26-32, 2013.

36. Mitchell PS, Parkin RK, Kroh EM, Fritz BR, Wyman SK, Pogosova-Agadjanyan EL, Peterson A, Noteboom J, O'Briant KC, Allen A, et al: Circulating microRNAs as stable blood-based markers for cancer detection. Proc Natl Acad Sci USA 105: 10513-10518, 2008.

37. Chen X, Ba Y, Ma L, Cai X, Yin Y, Wang K, Guo J, Zhang Y, Chen J, Guo X, et al: Characterization of microRNAs in serum: A novel class of biomarkers for diagnosis of cancer and other diseases. Cell Res 18: 997-1006, 2008.

38. Heneghan HM, Miller N, Lowery AJ, Sweeney KJ, Newell J and Kerin MJ: Circulating microRNAs as novel minimally invasive biomarkers for breast cancer. Ann Surg 251: 499-505, 2010.

39. Wang PY, Gong HT, Li BF, Lv CL, Wang HT, Zhou HH, Li XX, Xie SY and Jiang BF: Higher expression of circulating miR-182 as a novel biomarker for breast cancer. Oncol Lett 6: 1681-1686, 2013. 